\title{
Lipid levels in HIV-positive men receiving anti-retroviral therapy are not associated with copy number variation of reverse cholesterol transport pathway genes
}

\author{
Rebecca B. Marino', Lawrence A. Kingsley', Shehnaz K. Hussain², Jay H. Bream³, Sudhir Penogonda4,
} Priya Duggal ${ }^{3}$ and Jeremy J. Martinson ${ }^{1 *}$

\begin{abstract}
Background: The exacerbation of HIV-1 associated dyslipidemia seen in a subset of patients receiving anti-retroviral therapy suggests that genetic factors put these individuals at greater risk of cardiovascular disease. Single nucleotide polymorphisms (SNPs) within genes of and influencing the reverse cholesterol transport (RCT) pathway are associated with lipid levels but little is known regarding their copy number variation (CNV). This form of quantitative genetic variation has the potential to alter the amount of gene product made, thereby also influencing lipid metabolism.

Results: To examine if CNV in RCT pathway genes was associated with altered serum lipid profiles in HIV-positive individuals receiving therapy, we designed a custom multiplex ligation-dependent probe amplification assay to screen 16 RCT genes within a subset of individuals from the Multicenter AIDS Cohort Study who show extreme lipid phenotypes. Verification of CNV was performed using a custom NanoString assay, and the Illumina HT-12 mRNA expression microarray was used to determine the influence of copy number on gene expression. Among the RCT genes, CNV was observed to be extremely rare. The only CNV seen was in the CETP gene, which showed a loss of copy in 1 of the 320 samples $(0.3 \%)$ in our study. The genes in our study showed little variation in expression between individuals, and the variation seen was not related to any detected CNV.
\end{abstract}

Conclusions: Whole gene CNV is uncommon in RCT pathway genes, and not a major factor in the development of highly active antiretroviral therapy (HAART) associated dyslipidemia.

Keywords: CNV, Copy number variation, Dyslipidemia, HIV-1, Reverse cholesterol transport pathway, Anti-retroviral therapy

\section{Background}

Individuals infected with HIV-1 exhibit changes in serum lipid levels seen as hypercholesterolemia and hypertriglyceridemia [1-4]. Following antiretroviral therapy (ART), lipid levels remain skewed for many patients, as LDL-cholesterol (LDL-C) and triglycerides increase while HDL-cholesterol (HDL-C) remains lowered [1-3, 5-7].

\footnotetext{
*Correspondence: jmartins@pitt.edu

${ }^{1}$ Department of Infectious Diseases and Microbiology, Graduate School of Public Health, University of Pittsburgh, 130 De Soto St, Pittsburgh, PA 15261, USA

Full list of author information is available at the end of the article
}

Previous studies have shown that this dyslipidemic profile is associated with greater risk for cardiovascular disease (CVD), myocardial infarction and atherosclerosis in HIV-positive individuals [3, 5, 8-11]. As some in the HIV-1 infected population have begun to reach the age where CVD risk is increased and the affect of HIV infection on this risk in unknown, there is a need to understand the mechanisms behind therapy-associated lipid dysfunction. Many factors likely contribute towards this dyslipidemia, including the different drug components used in ART [12-14] as well as factors innate to the individual. The prevalence of dyslipidemia is high, but not 
all-inclusive, among the HIV-positive population suggesting that genetic factors potentially have a role [15]. Studies have already illustrated a broad genetic impact on lipids, as lipid levels and CVD risk vary based on ethnic background in HIV uninfected populations [16-18]. We have recently shown that biogeographical ancestry was significantly associated with lipid levels in a cohort of men who have sex with men (MSM), and that European ancestry results in a more atherogenic phenotype even after controlling for HIV and therapy components [19].

Furthermore, several genome-wide association studies (GWAS) have identified single nucleotide polymorphisms (SNPs) associated with CVD risk [20-25], many of which are present in genes involved in cholesterol metabolism and transport. One particularly relevant set of genes is that of the reverse cholesterol transport (RCT) pathway, which directly influences lipid levels. Polymorphisms in genes of this pathway, and in those directly interacting with it, contribute to the variance of lipid levels, and also alter expression levels of some of the genes themselves $[15,26-33]$. Recent studies have identified specific mutations located within RCT genes that are associated with altered lipid levels in individuals with HIV-associated atherogenic dyslipidemia. The SNP rs3135506, located in the APOA5 gene, was associated with increased triglycerides and decreased HDL-C, while a SNP in the $L P L$ gene, rs328, was associated with increased levels of HDL-C [34]. Additionally, common SNP genotypes in $A P O E$ were found to be associated with lipid levels where the E2 allele has a protective effect against dyslipidemia while the E4 is indicative of more risk [35]. Furthermore, expression levels of $L D L R$ can be modified by mutations in the proprotein-convertase subtilisin-kexin type 9 gene (PSCK9), ultimately resulting in altered levels of LDL-C $[27,36,37]$. Individuals with loss of function mutations in PCSK9 show decreased amounts of LDL-C while those with gain of function mutations have increased amounts [26, 33, 38].

In addition to posttranslational protein regulation such as that seen with PCSK9, protein levels of RCT gene products could also be influenced by copy number variation $(\mathrm{CNV})$. This type of genetic variation includes duplications, deletions, and inversions of DNA segments greater than 50 bp in size [39-42]. Previous studies on CNV in the CCL3L1 and DEFB4 genes illustrate that an increase in transcriptionally available copies of a gene not only results in increased expression levels but also increases in protein levels directly proportional to the number of copies [43-46]. Such variation in one or a few RCT genes has the potential to alter the functionality of this lipid metabolism pathway dramatically, and thereby influence serum HDL and LDL levels. Yet, while there have been a number of studies investigating the association of SNPs within these genes to lipid levels [28-32, 47], little has been documented related to their $\mathrm{CNV}$, apart from reports on rare structural variation in the $L D L R$ gene associated with Familial Hypercholesterolaemia [48-51] and the occasional reported variant in $L P L, A B C A 1$, and $L I P C[48,52]$. Furthermore, the Database of Genomic Variants, a compilation of structural variation in healthy control sample genomes, contains rare CNV encompassing the RCT genes [53].

Here, we designed a study employing custom Multiplex Ligation-dependent Probe Amplification (MLPA) and NanoString probes to screen for CNV in $16 \mathrm{RCT}$ associated genes in participants from the Multicenter AIDS Cohort Study (MACS), to identify if CNV is present, the degree to which it varies, and whether it has an association with the abnormal lipid metabolism observed in HIV-positive individuals undergoing antiretroviral therapy.

\section{Results}

\section{Sample demographics}

Using the 2005 clinic measurements, and the NCEP/ATP III report criteria [54] (HDL-C $\leq 40 \mathrm{mg} / \mathrm{dL}$ or $\geq 60 \mathrm{mg} /$ $\mathrm{dL} ; \mathrm{LDL}-\mathrm{C} \leq 100 \mathrm{mg} / \mathrm{dL}$ or $\geq 130 \mathrm{mg} / \mathrm{dL}$ ), 366 suitable MACS participants were identified, of which 319 were successfully analyzed using MLPA (Fig. 1). The demographic data for these 319 samples are summarized in Table 1. We identified 23 samples with an atheroprotective phenotype (HDL-C $\geq 60 \mathrm{mg} / \mathrm{dL}$ and LDL-C $\leq 100 \mathrm{mg} / \mathrm{dL}$ ) and 7 samples with an atherogenic phenotype (HDL-C $\leq 40 \mathrm{mg} / \mathrm{dL}$ and LDL-C $\geq 160 \mathrm{mg} / \mathrm{dL}$ ). Those with the atherogenic lipid profile had a higher mean body mass index (BMI), plus higher total cholesterol and triglyceride levels when compared to those who had the atheroprotective phenotype. Age among all lipid groups was similar, with a median age of 48 (IQR: 47-49). BMI was higher in the uninfected individuals within each grouping and, with the exception of the atheroprotective group, the mean BMI of most groups ranged from overweight to borderline obese.

Of the individuals who were HIV-positive during 2005 , over $70 \%$ were receiving a type of antiretroviral therapy (Potent ART, combination, or monotherapy defined according to the DHHS/Kaiser panel criteria [55]). Of those who reported therapy use, around three quarters had over $95 \%$ self-reported adherence. We also compared the distribution of Biogeographical Ancestry (BGA), recently determined for these samples [19], for the sample subset. The majority of samples in each group were those of European ancestry, followed by those of mixed African-European ancestry, and a few samples with Asian-European ancestry. However in the HIV-positive groups with high HDL-C $(\geq 60 \mathrm{mg} / \mathrm{dL})$ and in the 


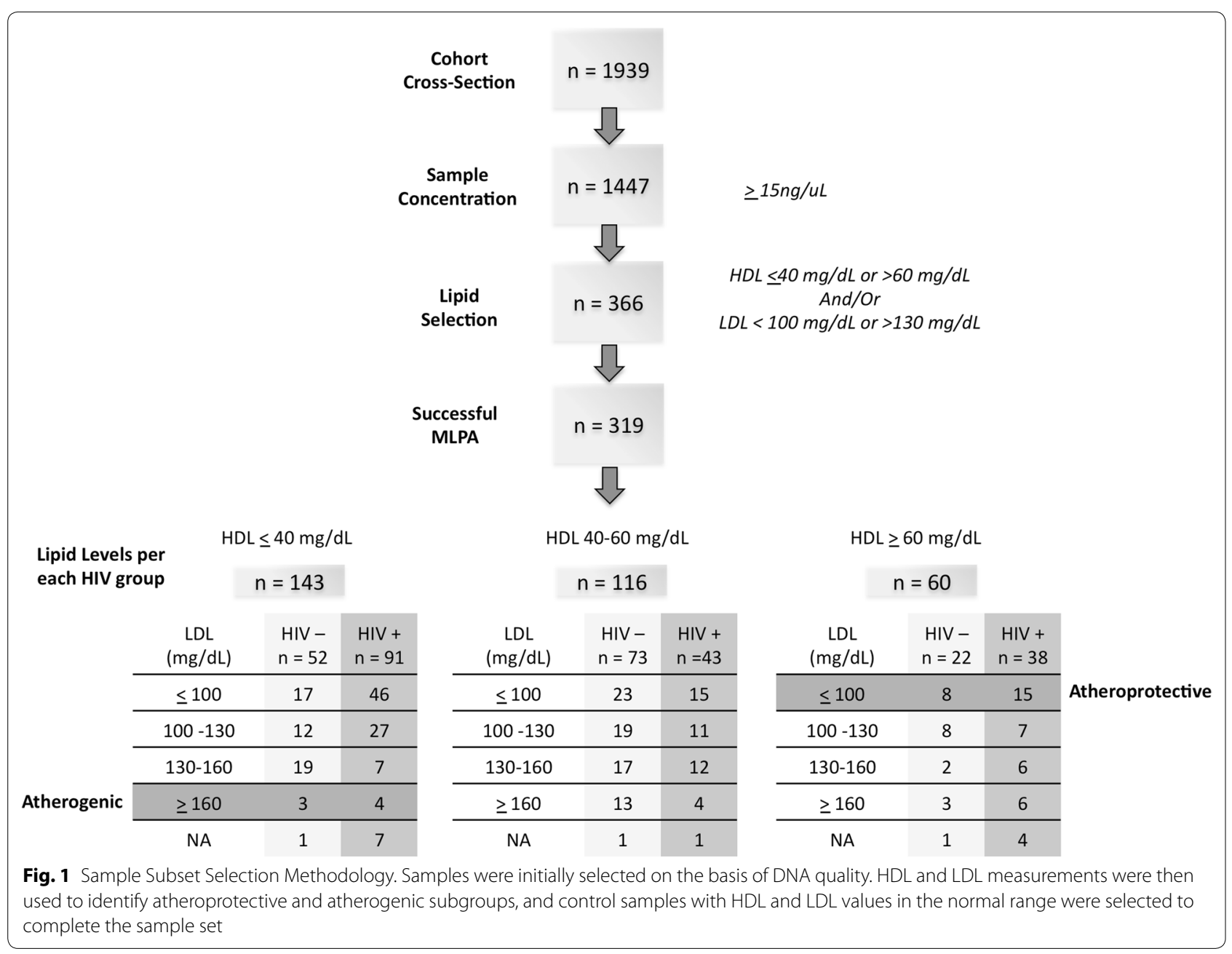

atheroprotective group, samples with African-European ancestry were in the majority.

\section{Multiplex ligation dependent probe amplification}

As reference samples with known copies of the RCT genes are not available, we identified experimental samples whose normalized peak height for each probe was similar to the sample set mean height. Using these samples as references, the coffalyser.net software calculated the probe ratios for each sample relative to the reference samples. Assuming that the most frequently observed ratio corresponded to two copies per diploid genome, ratios above 0.7 and below 1.3 are considered to be within the normal range of two copies [56]. Anything outside of these arbitrary MRC-Holland derived thresholds was identified as an outlier with potential CNV.

Of the 16 RCT pathway associated genes screened, only three ( $A P O A 4, C E T P$, and $A B C A 1)$ showed any signs of $\mathrm{CNV}$, and in each case the CNV was extremely rare. For each of these genes, a few individuals showed ratios that crossed or were at the lower threshold (Fig. 2). None of the RCT genes had CNV ratios that passed the upper ratio bound of 1.3, suggesting that no sample showed gains in copy number. Table 2 lists normalized ratios of the three genes for samples with losses along with the sample's 2005 visit HDL-C and LDL-C levels.

Two samples (123 and 367) had a loss of APOA4 copy number (with normalized ratios of 0.56 and 0.55 , respectively) while sample 157 had a loss of CETP copy number with a ratio of 0.65 . Sample 209 had a normalized ratio for $A B C A 1$ that fell on the 0.7 threshold indicating a possible loss. The standard deviations for each of these outlying probes were relatively small $(< \pm 0.05)$ indicating that the decrease in ratio observed was likely genuine. When MLPA was performed for a second time on these 4 samples, the observations were consistent with the first run. No clear association between any of these losses and lipid levels (Table 2) was apparent, although this observation is not conclusive due to the small number of samples involved. 
Table 1 Demographic and descriptive characteristics of study participants

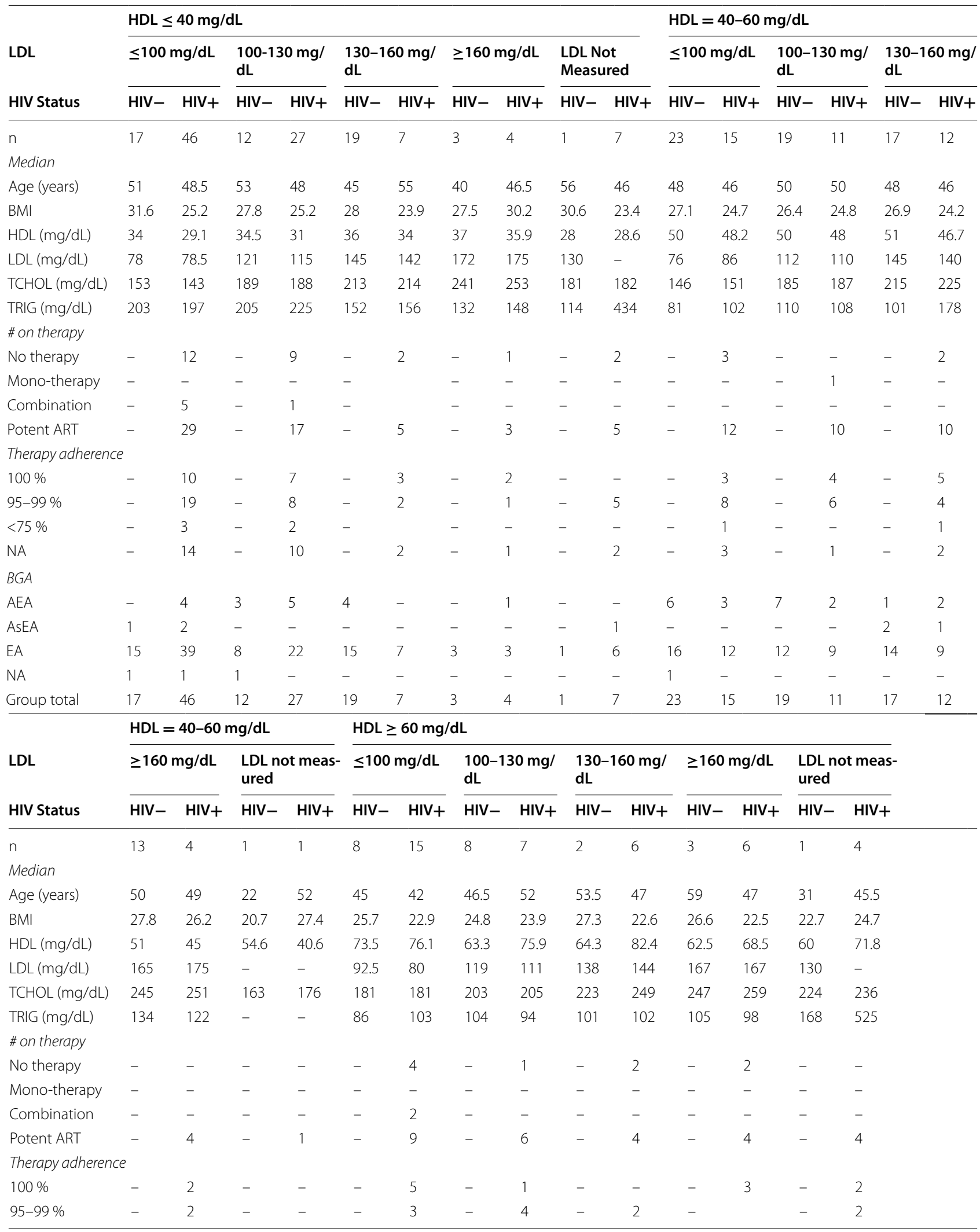


Table 1 continued

\begin{tabular}{|c|c|c|c|c|c|c|c|c|c|c|c|c|c|c|}
\hline \multirow{3}{*}{$\begin{array}{l}\text { LDL } \\
\text { HIV Status }\end{array}$} & \multicolumn{4}{|c|}{$\mathrm{HDL}=40-60 \mathrm{mg} / \mathrm{dL}$} & \multicolumn{10}{|c|}{$\mathrm{HDL} \geq 60 \mathrm{mg} / \mathrm{dL}$} \\
\hline & \multicolumn{2}{|c|}{$\geq 160 \mathrm{mg} / \mathrm{dL}$} & \multicolumn{2}{|c|}{$\begin{array}{l}\text { LDL not meas- } \\
\text { ured }\end{array}$} & \multicolumn{2}{|c|}{$\leq 100 \mathrm{mg} / \mathrm{dL}$} & \multicolumn{2}{|c|}{$\begin{array}{l}100-130 \mathrm{mg} / \\
\mathrm{dL}\end{array}$} & \multicolumn{2}{|c|}{$\begin{array}{l}130-160 \mathrm{mg} / \\
\mathrm{dL}\end{array}$} & \multicolumn{2}{|c|}{$\geq 160 \mathrm{mg} / \mathrm{dL}$} & \multicolumn{2}{|c|}{$\begin{array}{l}\text { LDL not meas- } \\
\text { ured }\end{array}$} \\
\hline & HIV- & HIV+ & HIV- & HIV+ & HIV- & $\mathrm{HIV}+$ & HIV- & $\mathrm{HIV}+$ & HIV- & HIV+ & HIV- & $\mathrm{HIV}+$ & HIV- & HIV+ \\
\hline$<75 \%$ & - & - & - & 1 & - & 3 & - & 1 & - & 2 & - & 1 & - & - \\
\hline NA & - & - & - & - & - & 4 & - & 1 & - & 2 & - & 2 & - & - \\
\hline \multicolumn{15}{|l|}{$B G A$} \\
\hline AEA & 3 & - & 1 & - & 1 & 11 & 3 & - & - & 4 & - & - & - & 1 \\
\hline AsEA & - & - & - & - & 1 & 3 & - & - & - & - & - & - & - & 1 \\
\hline EA & 10 & 4 & - & 1 & 6 & 1 & 5 & 7 & 2 & 2 & 3 & 5 & 1 & 2 \\
\hline NA & - & - & - & - & - & - & - & - & - & - & - & 1 & - & - \\
\hline Group total & 13 & 4 & 1 & 1 & 8 & 15 & 8 & 7 & 2 & 6 & 3 & 6 & 1 & 4 \\
\hline
\end{tabular}

BMI, body mass index; HDL-C, high density lipoprotein cholesterol; LDL-C, low density lipoprotein cholesterol; TCHOL, total cholesterol; TRIG, triglycerides; monotherapy, single nucleoside reverse transcriptase inhibitor; Combination, two or more nucleoside reverse transcriptase inhibitors; potent ART, two or more nucleoside reverse transcriptase inhibitors with a protease inhibitor or a nonnucleoside reverse transcriptase inhibitor; BGA, biogeographical ancestry; AEA, African/ European ancestry; EA, European ancestry; AsEA, Asian European ancestry

The interquartile ranges (IQR) for most of the RCT gene probes were narrow (0.04-0.09), and similar to those of the two-copy reference probes. This tight clustering of ratios around the mean of each probe further suggests that CNV is not common in the RCT genes. The only probes with wider IQRs were $A B C A 1$ and $S R B I$. While their IQRs were slightly broader than the other RCT probes, this spread of the ratio distribution was also seen in the properly functioning reference probes suggesting that this was within the normal range of our experiment (data not shown).

As gold standard referents containing known copy numbers of each RCT gene are not available, and the P300 reference probe set provided by MRC-Holland includes probes with a maximum number of two copies, we developed a quality control assay to ensure that our MLPA protocol was capable of picking up a range of CNV above 2 copies (Additional file 1: Supplementary Methods). Through use of control samples with known amounts of CNV, the MRC-Holland P139 Defensin MLPA assay, and our P300/RCT assay extended to include probes for variants in the DEFB103A and CCR5 genes, we were able to verify that our assay can identify a range of CNV even when the sample mean is used to define a referent (Additional file 2: Figure S2).

To determine whether the rare loss for the three RCT genes identified during MLPA reflected true CNV or problems with probe binding, Sanger sequencing was performed to examine the probe binding site for those individuals who showed losses, plus several control individuals who showed no changes in copy number. We determined that individuals who showed a loss in signal for $A P O A 4$ were heterozygous for a rare intronic SNP rs185210669, located 1 base from the internal ligation site for that probe. This mutant allele fails to bind the left MLPA probe oligo strongly, leading to impaired ligation to the right oligo and decreased MLPA signal. The other genes $(A B C A 1$ and $C E T P)$ contained no SNPs within their ligation sites.

\section{CNV confirmation by NanoString}

We confirmed our findings by using a custom NanoString assay to measure CNV of the RCT genes for 267 of the samples analyzed by MLPA. The CNV ratios generated mirrored those seen with MLPA (data not shown). We replicated the loss in copy number of CETP in sample 157 (copy number ratio of 0.58 ) but did not observe the losses for $A B C A 1$ in sample 209 (1.06) or APOA4 for both samples 123 and 367 (1.10 and 1.04). As the MLPA-derived ratio for $A B C A 1$ in sample 209 fell on the threshold value of 0.7 , it is likely that this sample does not in fact have a true loss in copies. It is also possible that MLPA probe used for $A B C A 1$ is picking up a rare small $C N V$ that is not detected by the NanoString probe, as the probes for these assays bind in different regions of the gene. The loss observed in APOA4 only by MLPA is attributed to the ligation-site SNP identified in the MLPA probe.

\section{Expression analysis}

We also determined the expression levels of the RCT genes in our study, using data extracted from a wholegenome transcription dataset obtained using the Illumina HT-12 platform. Gene expression levels on 127 samples were compared to both MLPA and NanoString $\mathrm{CNV}$ ratios. As expected, comparisons of MLPA- and NanoString-generated $\mathrm{CNV}$ ratios to log transformed mRNA expression levels yielded no significant associations (Fig. 3). 


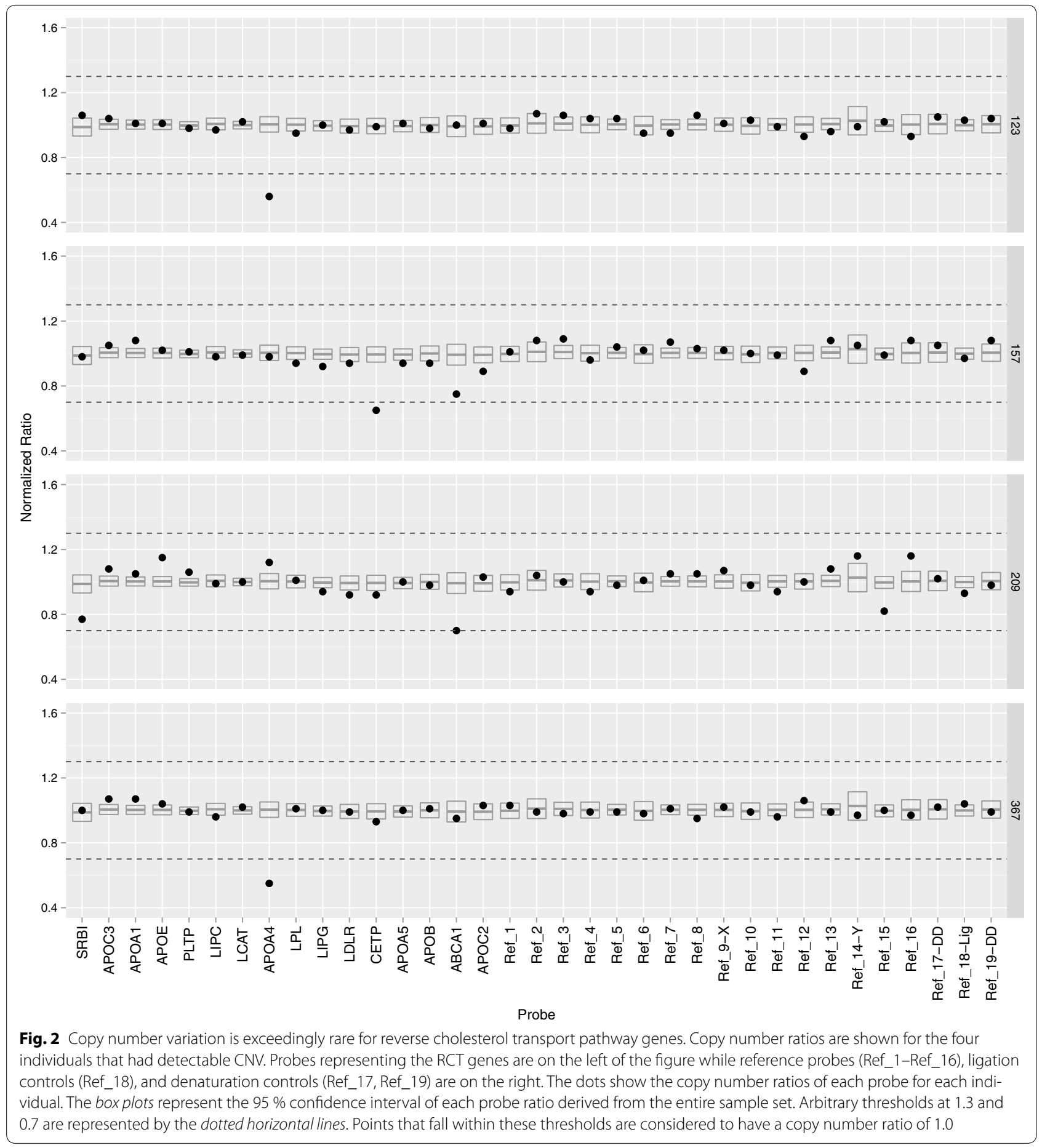

\section{Discussion}

The contribution of host genetic variation to the development of the CVD-associated side effects seen in response to antiretroviral therapy is still not fully understood. We have previously studied the roles of Biogeographical Ancestry [19], and of individual SNPs on this, but no studies have been done to date on the impact of quantitative genetic variation such as $\mathrm{CNV}$ on this process. To address this, we developed an MLPA assay, and used it to measure CNV in genes within the RCT pathway $[28,29]$. As extreme HDL and LDL abnormalities are observed in only a subset of HIV-positive patients 
Table 2 Normalized ratios of reverse cholesterol transport pathway gene CNV probes that showed significant departure from unity

\begin{tabular}{|c|c|c|c|c|c|c|}
\hline \multirow[b]{2}{*}{ Sample } & \multicolumn{2}{|l|}{ Lipid levels ${ }^{a}$} & \multicolumn{4}{|c|}{ Normalized ratios $^{\mathbf{b}}$} \\
\hline & $\mathrm{LDL}-\mathrm{C}, \mathrm{mg} / \mathrm{dL}$ & HDL-C, mg/dL & ABCA1 & APOA4 & CETP & SRBI \\
\hline 123 & $147(132.25-162.25)$ & $55(51-68.3)$ & 1 & $0.56^{*}$ & 0.99 & 1.06 \\
\hline 157 & $114(103-129)$ & $30(24.8-38.1)$ & 0.75 & 0.98 & $0.65^{*}$ & 0.98 \\
\hline 209 & $136.5(124.25-148.5)$ & $38(36-40.4)$ & $0.7^{*}$ & 1.12 & 0.92 & 0.77 \\
\hline 367 & $69(49-76)$ & $39.2(35.8-54.1)$ & 0.95 & $0.55^{*}$ & 0.93 & 1.0 \\
\hline
\end{tabular}

${ }^{a}$ The first two columns list median serum HDL-C and LDL-C levels from a minimum of 8 visits for that individual. Within the brackets is the IQR range for those lipid levels

b Probes that crossed or were on the 0.7 ratio threshold are indicated with $\left(^{*}\right)$

receiving anti-retroviral therapy and experiencing dyslipidemia [15], the susceptibility to these severe lipoprotein changes is likely to have a genetic component.

While previous studies have already found an association between sequence variation in genes within, and influencing, the RCT pathway and lipoprotein levels, we theorized that $\mathrm{CNV}$ in the RCT pathway could play a role in these extreme lipoprotein phenotypes. A region of duplication encompassing an entire gene and its regulatory regions has the capability to alter expression and protein levels in a manner directly proportional to the amount of copies present. Such a relationship is observed for the CCL3L1 and DEFB4 genes, where increases in gene products correspond to copies present for each gene up to a plateau point $[43,46]$. Even though this type of variation has the potential to influence lipid metabolism, the available information on whole gene $\mathrm{CNV}$ in the genes of the RCT pathway is limited to a few select genes ( $L D L R, L P L, A B C A 1$, and $L I P C)[48,52]$.

Data currently available within the Database of Genomic Variants [57] shows a limited amount of rare $\mathrm{CNV}$ present for the RCT genes. The documented CNV that is there consists primarily of insertions and deletions within the genes, rather than whole gene variation. Thus, it is unlikely that CNV for these genes is common in the general population, but our strategy here was to combine a population-based screen with a focused investigation of individuals with extreme lipid phenotypes (strongly atheroprotective vs. strongly atherogenic). Our hypothesis was that $\mathrm{CNV}$ encompassing the full length of a RCT gene would result in an increased or decreased amount of transcribed protein product directly proportional to the amount of copies present, thus impacting serum cholesterol levels. Further, we wished to investigate whether individuals with CNV in the central range would have normal lipid levels while those whose CNV was in the outermost edges of the range would have a dysregulated lipid metabolism leading to the extreme lipid profiles.
Our results in this study identified rare loss variants in 3 of the RCT genes. Out of 267 individuals and 16 genes studied with two different $\mathrm{CNV}$ assay procedures, $C E T P$ showed a loss in a single individual, and two genes (ABCA1 and APOA4) showed apparent copy number losses with MLPA. The apparent loss of copy number seen for $A P O A 4$ was determined to be due to a SNP in the ligation site of its MLPA probe while the apparent loss seen at $A B C A 1$ is suspected to be not genuine. The small standard deviation seen, along with the reproducibility of the significant loss of signal during additional MLPA runs, indicates that the loss for the CETP probe was valid. Coupled with the tight clustering around the normalized ratio of 1.0 for the non-outlying points of all of the RCT probes, these results strongly suggest that whole gene CNV is not present in the RCT genes at anything above very low levels, and is therefore not likely to be a major influence on lipid levels in either the normal population or those infected with HIV and receiving antiretroviral therapy.

These findings are consistent with previous reports of limited structural variation in the RCT genes, as presented in the Database of Genomic Variants [53, 57]. Within this database, deletions that included whole genes were observed for CETP. The $A B C A 1$ gene was observed to have a wide variety of insertions and deletions within its bounds, including five losses in the region of our MLPA probe, although none of them encompass the entire gene. All of these reported variants were extremely rare, with only a few individuals having the variant in studies containing several thousand participants. For those with higher frequencies, the study sizes were too small to conclude that a common variant was observed.

We also compared the ratios obtained with both $\mathrm{CNV}$ assays to gene expression data available for a subset of our samples. None of the genes for which we had available CNV data showed variation in expression level. This further suggests that it is unlikely that significant $\mathrm{CNV}$ is present in these genes that might affect expression. 


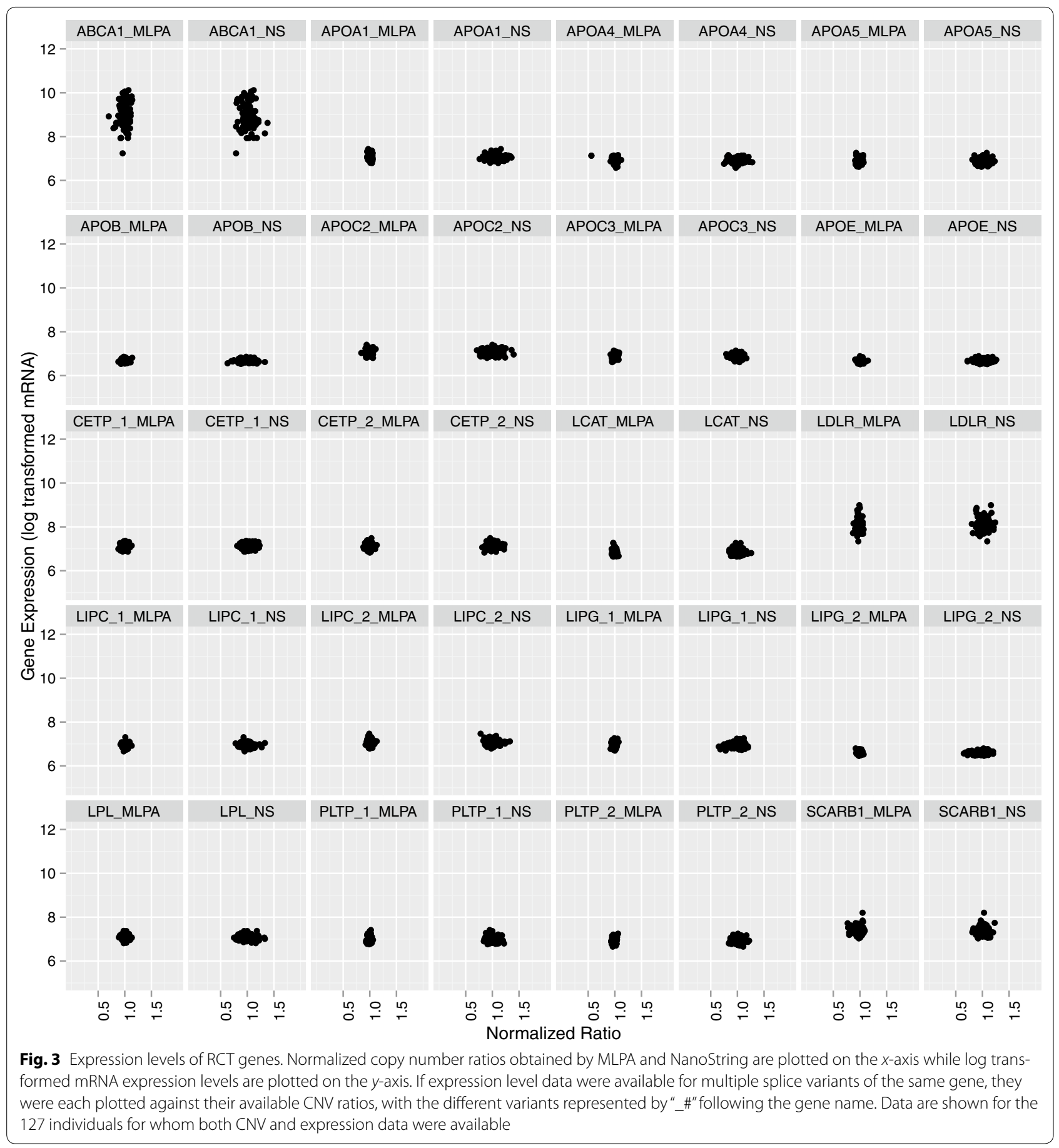

\section{Limitations}

Our study was designed to detect any gene-specific CNV in members of the RCT pathway that may impact levels of gene expression and subsequent enzymatic activity that therefore affect lipid levels and lead to dyslipidemia in members of our study cohort. Our study does have some limitations. As no prior survey of CNV in these genes had been attempted, the frequency of such variants was unknown and our study was exploratory. As such, it had limited statistical power to assess the impact of CNV between the atherogenic and atheroprotective groups. Also, the sizes of the atheroprotective $(n=23)$ and atheroprotective $(n=7)$ groups are not evenly matched, which would preclude more advanced statistical analysis 
were we to have found CNV in our samples, but the overall sample size of 319 individuals successfully typed is large enough to have detected any common variants and we can conclude that $\mathrm{CNV}$ of these genes is rare or absent. As we only designed one CNV probe set per gene it is also possible that variation within a gene could have been missed-for example, the LPA gene contains many kringle repeats that were not a focus of our study.

Our study was also limited by the type of clinical data available. In each biannual visit, serum cholesterol and triglyceride measurements are obtained from our study participants, and were used to define our atherogenic and atheroprotective groups. Other measurements, such as lipoprotein particle size and number, and HDL efflux capacity, have been shown to be stronger predictors of cardiovascular disease risk $[58,59]$, and would have been collected on subsequent visits had our initial study shown a role for $\mathrm{CNV}$ in this pathway. Our samples were also collected prior to the widespread use of the $2013 \mathrm{ACC} /$ AHA guideline, and we therefore use the older NCEP ATP III panel, but our data are based on a sufficiently large sample size to overcome this issue.

\section{Conclusions}

In this study we were able to develop a MLPA assay capable of detecting $\mathrm{CNV}$ when it is present. Using this assay we have illustrated that whole gene $\mathrm{CNV}$ is present only at very low levels in the RCT genes, and is not a major factor in the development of HAART-associated dyslipidemia. Thus, other host genetic influences exist and need to be identified before we are able to understand fully the ways in which host, viral, and therapeutic environmental factors interact to determine the outcome of antiretroviral therapy in HIV-positive individuals.

\section{Methods Samples}

Experimental samples were obtained from the Multicenter AIDS Cohort Study (MACS). The MACS is a multicenter (Baltimore, MD; Chicago, IL; Pittsburgh, PA; and Los Angeles, CA) ongoing prospective study, founded in 1984, of the natural and treated histories of HIV-1 infection in men who have sex with men. Participants attend clinics bi-annually for a physical exam and sample collection, and complete extensive questionnaires about their medical history, behavior changes, and overall quality of life. All samples were obtained from volunteer participants who had read and agreed to the consent policy implemented by the MACS for the protection of human subjects, and approved by the Institutional Review Board (IRB) at each MACS site (The University of Pittsburgh Institutional Review Board; The Johns Hopkins University Institutional Review Board; Northwestern University
Institutional Review Board; and The University of California, Los Angeles Medical Institutional Review Board).

Samples $(n=366)$ were identified on the basis of serum lipid measures obtained in their 2005 visit. We used the Third Report of the National Cholesterol Education Program (NCEP) Expert Panel on Detection, Evaluation, and Treatment of High Blood Cholesterol in Adults (Adult Treatment Panel III) [54] to identify lipid levels associated with higher risk of heart disease (HDL-C $<40 \mathrm{mg} / \mathrm{dL}$ and/or LDL-C $>130 \mathrm{mg} / \mathrm{dL}$ ) or with lower risk (HDL-C $>60 \mathrm{mg} / \mathrm{dL}$ and/or LDL-C $<100 \mathrm{mg} / \mathrm{dL}$ ) [60]. DNA was extracted from frozen peripheral blood mononuclear cell pellets using the Qiagen QIAamp DNA Blood Mini Kit, following the Blood and Body Fluid Spin Protocol. DNAs were stored at $-20^{\circ} \mathrm{C}$.

We also obtained 4 DNA control samples (NA07048, NA10846, NA10861, and NS12911) from the Coriell Institute cell repository. Three of these individuals served as reference samples, as the CNV of their DEFB103A gene was already known [61-63]. We also used 5 DNA samples obtained from volunteer donors in our laboratory as additional controls.

\section{Copy number variation detection by multiplex ligation-dependent probe amplification (MLPA)}

MLPA was performed using the MRC-Holland SALSA MLPA P300 Human DNA Reference-2 (Version: A1-0410) probemix kit, in conjunction with 16 custom probes for RCT pathway genes (Table 3). Custom probes were designed following the manufacturer's criteria (Synthetic Probe Design v10-update 04-02-2009) utilizing the human genome 18 reference assembly and the Stonybrook MLPA design browser (http://bioinform. arcan.stonybrook.edu/mlpa2/cgi-bin/mlpa.cgi) [64, 65]. BLAST searches were used to verify probe specificity prior to synthesis (Integrated DNA Technologies, Coralville, IA, USA). Additional 5'phosphorylation of the right-hand probe oligo was performed in our laboratory (Additional file 2: Table S1).

MLPA reactions were performed following the standard 1 tube protocol (MDP-v001, update 17-06-2011) with an 18-19 h hybridization and amplification step using the new universal primers (released in June 2011). Fragment separation was performed at the University of Pittsburgh Genomics and Proteomics Core Laboratories.

\section{Analysis of MLPA data}

The Coffalyser.net software (http://wiki.coffalyser.net) was used to perform fragment and comparative analysis. Initially, no reference samples were indicated, and samples with average signal across all probes were selected as references for each of the four 96 sample runs. Fragment analysis was then performed for a second time with 
Table 3 Reverse Cholesterol Transport (RCT) pathway genes selected for analysis

\begin{tabular}{|c|c|c|c|c|}
\hline Gene name & Symbol & $\begin{array}{l}\text { Chromo- } \\
\text { some }\end{array}$ & Function & References \\
\hline $\begin{array}{l}\text { Scavenger receptor class } B \text {, } \\
\text { member } 1\end{array}$ & SRBI & 12 & $\begin{array}{l}\text { Plasma membrane receptor for HDL that mediates transfer of } \\
\text { cholesterol to and from HDL }\end{array}$ & {$[33]$} \\
\hline Apolipoprotein C-III & APOC3 & 11 & $\begin{array}{l}\text { Very low density lipoprotein that inhibits lipoprotein lipase and } \\
\text { hepatic lipase delaying triglyceride-rich particle catabolism }\end{array}$ & {$[32]$} \\
\hline Apolipoprotein A-I & APOA1 & 11 & $\begin{array}{l}\text { Major protein component of HDL and a cofactor of LCAT. Defects } \\
\text { in APOA1 results in HDL deficiencies }\end{array}$ & {$[32,33]$} \\
\hline Apolipoprotein E & APOE & 19 & $\begin{array}{l}\text { Main apoprotein of chylomicron and essential for catabolism of } \\
\text { triglyceride-rich lipoprotein constituents }\end{array}$ & {$[32,33]$} \\
\hline Phospholipid Transfer Protein & PLTP & 20 & $\begin{array}{l}\text { Lipid transfer protein that transfers phospholipids from triglycer- } \\
\text { ide-rich lipoproteins to } \mathrm{HDL}\end{array}$ & {$[33]$} \\
\hline Hepatic Lipase & LIPC & 15 & $\begin{array}{l}\text { Triglyceride hydrolase and ligand/bridging factor for receptor } \\
\text { mediated lipoprotein uptake }\end{array}$ & {$[32,33]$} \\
\hline Lecithin-cholesterol Acyltransferase & LCAT & 16 & $\begin{array}{l}\text { Extracellular cholesterol esterifying enzyme that esterifies choles- } \\
\text { terol for transport }\end{array}$ & {$[32,33]$} \\
\hline Apolipoprotein A-IV & APOA4 & 11 & Potent activator of lecithin-cholesterol acyltransferase & {$[32]$} \\
\hline Lipoprotein Lipase & LPL & 8 & $\begin{array}{l}\text { Triglyceride hydrolase and ligand/bridging factor for receptor } \\
\text { mediated lipoprotein uptake }\end{array}$ & {$[32,33]$} \\
\hline Endothelial Lipase & LIPG & 18 & $\begin{array}{l}\text { Regulates circulating levels of HDL and acts has phospholipase } \\
\text { activity }\end{array}$ & {$[33]$} \\
\hline Low Density Lipoprotein Receptor & LDLR & 19 & $\begin{array}{l}\text { Cell surface protein involved in receptor-mediated endocytosis } \\
\text { of LDL }\end{array}$ & {$[32,33]$} \\
\hline Cholesteryl ester transfer protein & CETP & 16 & Transfers cholesteryl esters between lipoproteins & {$[32,33]$} \\
\hline Apolipoprotein A-V & APOA5 & 11 & Component of high density lipoprotein & {$[32]$} \\
\hline Apolipoprotein B & APOB & 2 & $\begin{array}{l}\text { Main apolipoprotein of chylomicrons and low density lipopro- } \\
\text { teins }\end{array}$ & {$[32]$} \\
\hline $\begin{array}{l}\text { ATP-binding cassette, sub-family A, } \\
\text { member } 1\end{array}$ & ABCA1 & 9 & $\begin{array}{l}\text { Membrane associated protein that functions as a cholesterol } \\
\text { efflux pump in the cellular lipid removal pathway }\end{array}$ & {$[32,33]$} \\
\hline Apolipoprotein C-II & APOC2 & 19 & Plasma lipid-binding protein that activates lipoprotein lipase & {$[32]$} \\
\hline
\end{tabular}

default settings. Samples with poor reference probe quality and reproducibility were removed before comparative analysis was performed for a second time. Final ratios and standard deviations were analyzed with the R statistical software package [66] and the following modules: ggplot2 [67], reshape [68], and gridExtra [69].

\section{Copy number calling}

For probes that lacked reference samples with known copy number levels, discrete copies were not calculated. Instead, the default ratio thresholds $(0.7,1.3)$, defined by MRC-Holland and based on a 2-copy reference sample (MLPA Results Interpretation-V02.2;11-02-2010) [70], were used to identify individuals who exhibited a gain $(>1.3)$ or loss $(<0.7)$ of copy number. The interquartile range (IQR) of each probe was also compared to that of the reference probes to identify experimental probes with potential CNV that did not cross the default threshold. If a reference sample with a known discrete copy number was available for a given probe, the discrete copy number of the experimental samples was determined by cluster analysis of raw copy number calls [71] (Additional file 1:
Supplementary Methods; Additional file 2: Figure S1 and Table S2).

\section{CNV confirmation assay}

A NanoString nCounter custom CNV CodeSet was designed containing the 16 RCT genes analyzed in our MLPA assay, and used to type 267 of the experimental samples previously typed by MLPA. DNA was processed and analyzed using a NanoString Technologies nCounter system at the University of Pittsburgh Genomics and Proteomics Core Laboratories. The NanoString nSolver Analysis Software (v1.1) was used to generate normalized ratios from raw counts, with 34 of the original MLPA samples set as RCT references.

\section{Gene expression analysis}

Gene expression data were available for 127 of the samples studied by MLPA and NanoString. These were obtained from whole blood collected into PAXgene tubes, from which RNA was extracted using the PAXgene Blood RNA Kit IVD. Samples were quantified, processed, and analyzed using the Illumina Human HT-12 v.4 whole-genome 
expression array at the University of Pittsburgh Genomics and Proteomics Core Laboratories. Raw data was exported from Illumina Genome Studio and further data analysis was performed using the Bioconductor $\mathrm{R}$ modules lumi [72] and ArrayQualityMetrics [73].

\section{Availability of supporting data}

Data are held by the Center for Analysis and Management of the Multicenter AIDS Cohort Study (CAMACS). For access to the MACS data, please complete the collaboration concept sheet and identify the article for which the data were used. This form and instructions may be found at: http://statepi.jhsph.edu/macs/forms.html.

\section{Additional files}

Additional file 1. Supplementary Methods. File Format: PDF.

Additional file 2. Supplemental Figures and Tables. Figure S1. Reproducible Typing of Rounded Whole Copy Number Calls depends on Distribution of Raw Copy Numbers around Whole Integer Values. Figure S2. Probes and reference samples demonstrating a range of CNV further Illustrate the rare nature of CNV in the RCT genes. Table S1. Custom MLPA Probe Specifics. Table S2. Accuracy of Copy Number Calls is Dependent on Method of Calling. File Format: PDF.

\begin{abstract}
Abbreviations
ACC/AHA: American College of Cardiology/American Heart Association; ART: antiretroviral therapy; BGA: biogeographical ancestry; CNV: copy number variation; CVD: cardiovascular disease; DNA: deoxyribonucleic acid; GWAS: Genome-Wide Association Study; HDL-C: high density lipoprotein cholesterol; HIV: human immunodeficiency virus; LDL-C: low density lipoprotein cholesterol; MACS: Multicenter AIDS Cohort Study; MLPA: multiplex ligation-dependent probe amplification; MSM: men who have sex with men; NCEP/ATP III: national cholesterol education program/adult treatment panel, third report;
\end{abstract} RCT: reverse cholesterol transport; SNP: single nucleotide polymorphism.

\section{Authors' contributions}

JM and RM conceived of the study. LK provided assistance with experimental design and sample section. SH, JB, SP, and PD contributed samples for the study. RM designed and performed the laboratory experiments (MLPA, DNA extraction, Nanostring, etc.) as well as analyzed the results. RM and JM drafted the original manuscript. All authors read and approved the final manuscript.

\section{Author details \\ 1 Department of Infectious Diseases and Microbiology, Graduate School of Public Health, University of Pittsburgh, 130 De Soto St, Pittsburgh, PA 15261, USA. ${ }^{2}$ Division of Hematology/Oncology, Department of Medicine, Cedars-Sinai Medical Center, 8700 Beverly Blvd, Los Angeles, CA 90048, USA. ${ }^{3}$ Bloomberg School of Public Health, Johns Hopkins University, 615 Wolfe St, Baltimore, MD 21205, USA. ${ }^{4}$ Feinberg School of Medicine, Northwestern University, 645 N Michigan Avenue, Chicago, IL 60611, USA.}

\section{Acknowledgements}

Data in this article were collected by the Multicenter AIDS Cohort Study (MACS) with centers (principal investigators) at The Johns Hopkins Bloomberg School of Public Health (Joseph B. Margolick, Lisa P. Jacobson), Howard Brown Health Center, Feinberg School of Medicine, Northwestern University, and Cook County Bureau of Health Services (John P. Phair, Steven M. Wolinsky), University of California, Los Angeles (Roger Detels), and University of Pittsburgh (Charles R. Rinaldo). The MACS is funded by the National Institute of Allergy and Infectious Diseases, with additional supplemental funding from the National Cancer Institute. UO1- Al-35042, UL1-RR025005, UO1-AI-35043, UO1-Al-35039, U01-Al-35040, UO1-Al-35041. Website located at http://www. statepi.jhsph.edu/macs/macs.html. A special thanks to Matthew Nicholaou for his help in extracting the DNA samples.

\section{Competing interests}

The authors declare that they have no competing interests.

Received: 1 October 2014 Accepted: 2 November 2015

Published online: 21 November 2015

\section{References}

1. Grunfeld C, Pang M, Doerrler W, Shigenaga J, Jensen P, Feingold K. Lipids, lipoproteins, triglyceride clearance, and cytokines in human immunodeficiency virus infection and the acquired immunodeficiency syndrome. J Clin Endocrinol Metab. 1992;74:1045-52.

2. Riddler SA. Impact of HIV Infection and HAART on Serum Lipids in Men. JAMA J Am Med Assoc. 2003;289:2978-82.

3. Friis-Møller N, Weber R, Reiss P, Thiébaut R, Kirk O, D'Arminio Monforte A, Pradier C, Morfeldt L, Mateu S, Law M, El-Sadr W, De Wit S, Sabin CA, Phillips AN, Lundgren JD. D:A: D Study Group: Cardiovascular disease risk factors in HIV patients-association with antiretroviral therapy. Results from the DAD study. AIDS. 2003;17:1179-93.

4. Hadigan C, Meigs JB, Corcoran C, Rietschel P, Piecuch S, Basgoz N, Davis B, Sax P, Stanley T, Wilson P, D’Agostino RB, Grinspoon S. Metabolic abnormalities and cardiovascular disease risk factors in adults with human immunodeficiency virus infection and lipodystrophy. Clin Infect Dis. 2001;32:130-9.

5. Hadigan C, Meigs JB, Corcoran C, Rietschel P, Piecuch S, Basgoz N, Davis B, Sax P, Stanley T, Wilson PW, D'Agostino RB, Grinspoon S. Metabolic abnormalities and cardiovascular disease risk factors in adults with human immunodeficiency virus infection and lipodystrophy. Clin Infect Dis. 2001;32:130-9.

6. Fontas E, van Leth F, Sabin CA, Friis-Møller N, Rickenbach M, d'Arminio Monforte A, Kirk O, Dupon M, Morfeldt L, Mateu S, Petoumenos K, El-Sadr W, De Wit S, Lundgren JD, Pradier C, Reiss P. D:A: D Study Group: Lipid profiles in HIV-infected patients receiving combination antiretroviral therapy: are different antiretroviral drugs associated with different lipid profiles? J Infect Dis. 2004;189:1056-74.

7. Riddler SA, Li X, Otvos J, Post W, Palella F, Kingsley L, Visscher B, Jacobson $L P$, Sharrett AR. Antiretroviral therapy is associated with an atherogenic lipoprotein phenotype among HIV-1-infected men in the multicenter AIDS cohort study. J Acquir Immune Defic Syndr. 2008;48:281-8.

8. Worm SW, Kamara DA, Reiss P, Kirk O, El-Sadr W, Fux C, Fontas E, Phillips A, D'Arminio Monforte A, De Wit S, Petoumenos K, Friis-Mller N, Mercie P, Lundgren JD, Sabin C. Elevated triglycerides and risk of myocardial infarction in HIV-positive persons. AIDS. 2011;25:1497-504.

9. Janiszewski PM, Ross R, Despres J-P, Lemieux I, Orlando G, Carli F, Bagni P, Menozzi M, Zona S, Guaraldi G. Hypertriglyceridemia and Waist Circumference Predict Cardiovascular Risk among HIV Patients: A Cross-Sectional Study. PLOS ONE. 2011;6:e25032.

10. Duprez DA, Kuller LH, Tracy R, Otvos J, Cooper DA, Hoy J, Neuhaus J, Paton NI, Friis-Møller N, Lampe F, Liappis AP, Neaton JD. Lipoprotein particle subclasses, cardiovascular disease and HIV infection. Atherosclerosis. 2009;207:524-9.

11. Friis-Møller N, Reiss P, Sabin CA, Weber R, Monforte AD, El-Sadr W, De Wit S, Kirk O, Fontas E, Law MG, Phillips A, Lundgren JD, Grp DS. Class of antiretroviral drugs and the risk of myocardial infarction. N Engl J Med. 2007:356:1723-35.

12. Duro M, Sarmento-Castro R, Almeida C, Medeiros R, Rebelo I: Lipid profile changes by high activity anti-retroviral therapy. Clin Biochem 2013.

13. Reyskens KMSE, Essop MF. HIV protease inhibitors and onset of cardiovascular diseases: a central role for oxidative stress and dysregulation of the ubiquitin-proteasome system. Biochim Biophys Acta. 2014;1842:256-68.

14. Srinivasa S, Grinspoon SK. Metabolic and body composition effects of newer antiretrovirals in HIV-infected patients. Eur J Endocrinol. 2014;170:R185-202.

15. Egaña-Gorroño L, Martínez E, Cormand B, Escribà T, Gatell J, Arnedo M. Impact of genetic factors on dyslipidemia in HIV-infected patients starting antiretroviral therapy. AIDS. 2013;27:529-38. 
16. Johnson JL, Slentz CA, Duscha BD, Samsa GP, McCartney JS, Houmard JA Kraus WE. Gender and racial differences in lipoprotein subclass distributions: the STRRIDE study. Atherosclerosis. 2004;176:371-7.

17. Kuller LH. Ethnic differences in atherosclerosis, cardiovascular disease and lipid metabolism. Curr Opin Lipidol. 2004;15:109-13.

18. D'Adamo E, Northrup V, Weiss R, Santoro N, Pierpont B, Savoye M, O'Malley G, Caprio S. Ethnic differences in lipoprotein subclasses in obese adolescents: importance of liver and intraabdominal fat accretion. Am J Clin Nutr. 2010;92:500-8.

19. Nicholaou MJ, Martinson JJ, Abraham AG, Brown TT, Hussain SK, Wolinsky SM, Kingsley LA. HAART-Associated Dyslipidemia Varies by Biogeographical Ancestry in the Multicenter AIDS Cohort Study. AIDS Res Hum Retroviruses. 2013;29:871-9.

20. Raman K, Chong M, Akhtar-Danesh GG, D'Mello M, Hasso R, Ross S, Xu F, Paré G. Genetic Markers of Inflammation and Their Role in Cardiovascular Disease. CJCA. 2013;29:67-74.

21. McPherson R. From Genome-Wide Association Studies to Functional Genomics: New Insights Into Cardiovascular Disease. CJCA. 2013;29:23-9.

22. Dubé JB, Hegele RA. Genetics 100 for cardiologists: basics of genomewide association studies. CJCA. 2013;29:10-7.

23. Sawhney $V$, Brouilette $S$, Abrams D, Schilling R, O'Brien B. Current genomics in cardiovascular medicine. Curr Genomics. 2012;13:446-62.

24. Swerdlow DI, Holmes MV, Harrison S, Humphries SE. The genetics of coronary heart disease. Br Med Bull. 2012;102:59-77.

25. Patel RS, Ye S. Genetic determinants of coronary heart disease: new discoveries and insights from genome-wide association studies. Heart. 2011;97:1463-73.

26. Cohen J, Pertsemlidis A, Kotowski IK, Graham R, Garcia CK, Hobbs HH. Low LDL cholesterol in individuals of African descent resulting from frequent nonsense mutations in PCSK9. Nat Genet. 2005;37:161-5.

27. Lopez D. PCSK9: an enigmatic protease. Biochim Biophys Acta. 2008;1781:184-91.

28. Knoblauch H. Haplotypes and SNPs in 13 lipid-relevant genes explain most of the genetic variance in high-density lipoprotein and low-density lipoprotein cholesterol. Hum Mol Genet. 2004;13:993-1004.

29. Morabia A. Association of extreme blood lipid profile phenotypic variation with 11 reverse cholesterol transport genes and 10 non-genetic cardiovascular disease risk factors. Hum Mol Genet. 2003;12:2733-43.

30. Arnedo M, Taffé P, Sahli R, Furrer H, Hirschel B, Elzi L, Weber R, Vernazza P, Bernasconi E, Darioli R, Bergmann S, Beckmann JS, Telenti A, Tarr PE. Swiss HIV Cohort Study: contribution of 20 single nucleotide polymorphisms of 13 genes to dyslipidemia associated with antiretroviral therapy. Pharmacogenet Genomics. 2007;17:755-64.

31. Thompson A, Di Angelantonio E, Sarwar N, Erqou S, Saleheen D, Dullaart RPF, Keavney B, Ye Z, Danesh J. Association of cholesteryl ester transfer protein genotypes with CETP mass and activity, lipid levels, and coronary risk. JAMA. 2008;299:2777-88.

32. Kathiresan S, Melander O, Anevski D, Guiducci C, Burtt NP, Roos C, Hirschhorn JN, Berglund G, Hedblad B, Groop L, Altshuler DM, NewtonCheh C, Orho-Melander M. Polymorphisms associated with cholesterol and risk of cardiovascular events. N Engl J Med. 2008;358:1240-9.

33. Guella II, Asselta RR, Ardissino DD, Merlini PAP, Peyvandi FF, Kathiresan SS, Mannucci PMP, Tubaro MM, Duga SS. Effects of PCSK9 genetic variants on plasma LDL cholesterol levels and risk of premature myocardial infarction in the Italian population. The Journal of Lipid Research. 2010:51:3342-9.

34. Echeverría P, Guardiola M, González M, Carles Vallvé J, Puig J, Bonjoch A, Clotet B, Ribalta J, Negredo E. Polymorphisms in LPL, CETP, and HL protect HIV-infected patients from atherogenic dyslipidemia in an allele-dosedependent manner. J Int AIDS Soc 2014;17

35. SuwalakT, Srisawasdi P, Puangpetch A, Santon S, Koomdee N, Chamnanphon M, Charoenyingwattana A, Chantratita W, Sukasem C. Polymorphisms of the ApoE (Apolipoprotein E) gene and their influence on dyslipidemia in HIV-1-infected individuals. Jpn J Infect Dis. 2015;68:5-12.

36. Lagace TA, Curtis DE, Garuti R, MCNutt MC, Park SW, Prather HB, Anderson NN, Ho YK, Hammer RE, Horton JD. Secreted PCSK9 decreases the number of LDL receptors in hepatocytes and in livers of parabiotic mice. J Clin Invest. 2006;1 16:2995-3005.

37. Cameron JJ, Holla ØLØ, Ranheim TT, Kulseth MAM, Berge KEK, Leren TPT. Effect of mutations in the PCSK9 gene on the cell surface LDL receptors. Hum Mol Genet. 2006;15:1551-8.
38. Benn M, Nordestgaard BG, Grande P, Schnohr P, Tybjaerg-Hansen A. PCSK9 R46L, Low-density lipoproteincholesterol levels, and risk of ischemic heart disease. JAC. 2010;55:2833-42.

39. Feuk L, Carson AR, Scherer SW. Structural variation in the human genome. Nat Rev Genet. 2006;7:85-97.

40. 1000 Genomes Project Consortium, Abecasis GR, Altshuler D, Auton A, Brooks LD, Durbin RM, Gibbs RA, Hurles ME, McVean GA. A map of human genome variation from population-scale sequencing. Nature 2011:467:1061-1073.

41. Redon R, Ishikawa S, Fitch KR, Feuk L, Perry GH, Andrews TD, Fiegler $H$, Shapero MH, Carson AR, Chen W, Cho EK, Dallaire S, Freeman JL, González JR, Gratacòs M, Huang J, Kalaitzopoulos D, Komura D, Macdonald JR, Marshall CR, Mei R, Montgomery L, Nishimura K, Okamura K, Shen F, Somerville MJ, Tchinda J, Valsesia A, Woodwark C, Yang F, et al. Global variation in copy number in the human genome. Nature. 2006;444:444-54.

42. Eichler EE, Nickerson DA, Altshuler D, Bowcock AM, Brooks LD, Carter NP, Church DM, Felsenfeld A, Guyer M, Lee C, Lupski JR, Mullikin JC, Pritchard JK, Sebat J, Sherry ST, Smith D, Valle D, Waterston RH. Completing the map of human genetic variation. Nature. 2007;447:161-5.

43. Hollox EJ, Armour JAL, Barber JCK. Extensive normal copy number variation of a beta-defensin antimicrobial-gene cluster. The American Journal of Human Genetics. 2003;73:591-600.

44. Stranger BE, Forrest MS, Dunning M, Ingle CE, Beazley C, Thorne N, Redon R, Bird CP, de Grassi A, Lee C, Tyler-Smith C, Carter N, Scherer SW, Tavare S, Deloukas P, Hurles ME, Dermitzakis ET. Relative Impact of Nucleotide and Copy Number Variation on Gene Expression Phenotypes. Science. 2007:315:848-53.

45. Groth M, Wiegand C, Szafranski K, Huse K, Kramer M, Rosenstiel P, Schreiber S, Norgauer J, Platzer M. Both copy number and sequence variations affect expression of human DEFB4. Genes Immun. 2010;11:458-66.

46. Townson JR, Barcellos LF, Nibbs RJ. Gene copy number regulates the production of the human chemokine CCL3-L1. Eur J Immunol. 2002:32:3016-26.

47. Cohen JC, Boerwinkle E, Mosley TH, Hobbs HH. Sequence variations in PCSK9, low LDL, and protection against coronary heart disease. N Engl J Med. 2006;354:1264-72

48. Lanktree M, Hegele RA. Copy number variation in metabolic phenotypes. Cytogenet Genome Res. 2008;123:169-75.

49. Chmara MM, Wasag BB, Zuk MM, Kubalska JJ, Wegrzyn AA, BednarskaMakaruk MM, Pronicka EE, Wehr HH, Defesche JCJ, Rynkiewicz AA, Limon JJ. Molecular characterization of Polish patients with familial hypercholesterolemia: novel and recurrent LDLR mutations. J Appl Genet. 2010;51:95-106.

50. Goldmann R, Tichý L, Freiberger T, Zapletalová P, Letocha O, Soška V, Fajkus J, Fajkusová L. Genomic characterization of large rearrangements of the LDLR gene in Czech patients with familial hypercholesterolemia. BMC Med Genet. 2010;11:115.

51. Futema M, Plagnol V, Whittall RA, Neil HA, Simon Broome Register Group, Humphries SE, UK10K. Use of targeted exome sequencing as a diagnostic tool for Familial Hypercholesterolaemia. J Med Genet. 2012;49:644-9.

52. Wang J, Ban MR, Hegele RA. Multiplex ligation-dependent probe amplification of LDLR enhances molecular diagnosis of familial hypercholesterolemia. J Lipid Res. 2005:46:366-72.

53. MacDonald JR, Ziman R, Yuen RKC, Feuk L, Scherer SW. The Database of Genomic Variants: a curated collection of structural variation in the human genome. Nucleic Acids Res. 2013;42:D986-92.

54. National Cholesterol Education Program NCEP Expert Panel on Detection Evaluation, and Treatment of High Blood Cholesterol in Adults (Adult Treatment Panel III). Third Report of the National Cholesterol Education Program (NCEP) Expert Panel on Detection, Evaluation, and Treatment of High Blood Cholesterol in Adults (Adult Treatment Panel III) final report. Circulation. 2002;106:3143-421.

55. Panel on Antiretroviral Guidelines for Adults \& Adolescents: Guidelines for using antiretroviral agents among HIV-infected adults and adolescents.

56. Results Interpretation [http://www.mlpa.com].

57. lafrate AJ, Feuk L, Rivera MN, Listewnik ML, Donahoe PK, Qi Y, Scherer SW, Lee $C$. Detection of large-scale variation in the human genome. Nature Publishing Group. 2004:36:949-51.

58. Srisawasdi P, Suwalak T, Sukasem C, Chittamma A, Pocathikorn A, Vanavanan S, Puangpetch A, Santon S, Chantratita W, Kiertiburanakul S, Kroll MH. Small-dense LDL cholesterol/large-buoyant LDL cholesterol ratio as 
an excellent marker for indicating lipodystrophy in HIV-infected patients. Am J Clin Pathol. 2013;140:506-15.

59. Mora S, Glynn RJ, Ridker PM. High-density lipoprotein cholesterol, size, particle number, and residual vascular risk after potent statin therapy. Circulation. 2013;128:1189-97.

60. Roger VL, Go AS, Lloyd-Jones DM, Benjamin EJ, Berry JD, Borden WB, Bravata DM, Dai S, Ford ES, Fox CS, Fullerton HJ, Gillespie C, Hailpern SM, Heit JA, Howard VJ, Kissela BM, Kittner SJ, Lackland DT, Lichtman JH, Lisabeth LD, Makuc DM, Marcus GM, Marelli A, Matchar DB, Moy CS, Mozaffarian D, Mussolino ME, Nichol G, Paynter NP, Soliman EZ, et al. Heart Disease and Stroke Statistics-2012 Update: A Report From the American Heart Association. Circulation. 2012;125:e2-220.

61. Fode P, Jespersgaard C, Hardwick RJ, Bogle H, Theisen M, Dodoo D, Lenicek M, Vitek L, Vieira A, Freitas J, Andersen PS, Hollox EJ. Determination of beta-defensin genomic copy number in different populations: a comparison of three methods. PLOS ONE. 2011;6:e16768.

62. Groth M, Szafranski K, Taudien S, Huse K, Mueller O, Rosenstiel P, Nygren AO, Schreiber S, Birkenmeier G, Platzer M. High-resolution mapping of the 8 p23.1 beta-defensin cluster reveals strictly concordant copy number variation of all genes. Hum Mutat. 2008;29:1247-54

63. Armour JAL, Palla R, Zeeuwen PLJM, Heijer MD, Schalkwijk J, Hollox EJ. Accurate, high-throughput typing of copy number variation using paralogue ratios from dispersed repeats. Nucleic Acids Res. 2007;35:e19.
64. Zhi J. MAPD: a probe design suite for multiplex ligation-dependent probe amplification assays. BMC Res Notes. 2010;3:137.

65. Zhi J, Hatchwell E. Human MLPA Probe Design (H-MAPD): a probe design tool for both electrophoresis-based and bead-coupled human multiplex ligation-dependent probe amplification assays. BMC Genom. 2008;9:407.

66. R Core Team. R: a Language and Environment for Statistical Computing. Vienna, Austria; 2012.

67. Wickham H: Ggplot2: Elegant Graphics for Data Analysis. Springer New York, 2009.

68. Wickham H. Reshaping data with the reshape package. J Stat Softw. 2007;21:1-20.

69. Auguie B: gridExtra: functions in Grid graphics. R package version 0.9.1. 2012.

70. MRC-Holland: Interpretation of MLPA results. 2010:1-7.

71. Field SF, Howson JMM, Maier LM, Walker S, Walker NM, Smyth DJ, Armour JAL, Clayton DG, Todd JA. Experimental aspects of copy number variant assays at CCL3L1. Nat Med. 2009;15:1115-7.

72. Du P, Kibbe WA, Lin SM. lumi: a pipeline for processing Illumina microarray. Bioinformatics. 2008;24:1547-8.

73. Kauffmann A, Gentleman R, Huber W. arrayQualityMetrics-a bioconductor package for quality assessment of microarray data. Bioinformatics. 2009:25:415-6.

\section{Submit your next manuscript to BioMed Central and take full advantage of:}

- Convenient online submission

- Thorough peer review

- No space constraints or color figure charges

- Immediate publication on acceptance

- Inclusion in PubMed, CAS, Scopus and Google Scholar

- Research which is freely available for redistribution

Submit your manuscript at

www.biomedcentral.com/submit

C Biomed Central 